\title{
Brasil: da identidade à marca
}

\section{RESUMO}

Com o título "Brasil: da identidade à marca", busca-se evidenciar, na trajetória brasileira, o pensamento da nação como um "construto" que, após estar longamente vinculado a um discurso do Estado e ao projeto nacional, hoje, liga-se progressivamente ao mercado. É esta passagem que buscaremos enfocar por meio das conexões entre corpo, moda, cultura e Brasil, tendo como pano de fundo a questão identitária, o desenvolvimento das novas tecnologias da comunicação e do marketing, da produção têxtil, do design e a progressiva globalização da economia.

\section{PALAVRAS-CHAVE}

- identidade

- nacionalidade

- consumo

\section{ABSTRACT}

Under the title of "Brazil: from Identity to Brand", attempts are made to highlight the mindset of the nation as a construct in the history of Brazil that is today linked progressively to the market, having long been bound to State discourse and nationalistic projects. This transition is analyzed through connections between the body, fashion, culture and Brazil, set against a backdrop of issues related to identity and the development of new communication and marketing technologies, fabric production, design and steadily-expanding economic globalization.

\section{KEY WORDS}

- identity

- nacionality

- market
C om o tífulo "Brasil: da identidade à marca", busca-se evidenciar, na trajetória brasileira, o pensamento da nação como um "construto" que, após estar longamente vinculado a um discurso do Estado e ao projeto nacional, hoje, liga-se progressivamente ao mercado. É esta passagem que buscaremos enfocar por meio das conexões entre corpo, moda, cultura e Brasil, tendo como pano de fundo a questão identitária, o desenvolvimento das novas tecnologias da comunicação e do marketing, da produção têxtil, do design e a progressiva globalização da economia.

O corpo funcionará como uma espécie de operador simbólico no quadro de uma antropologia do consumo. Seguindo pistas sobre o assunto, dadas por Mary Douglas e Baron Isherwood, ${ }^{1}$ a leitura do consumo, de alguma forma, reconstrói dados sobre a cultura de uma época e de um país. O consumo de bens materiais e simbólicos é ativo e constante no nosso cotidiano como estruturador de valores que constróem identidade, regulam relações sociais e definem mapas culturais. A elaboração de um pensamento capaz de ler os significados culturais do consumo, possui, assim, grande importância antropológica e comunicacional já que os bens são investidos de valores para expressar idéias, princípios, provocar transformações e criar permanências.

Algumas categorias foram por nós estabelecidas entre os anos 50 e 2000 relacionando o corpo e o universo da moda: moda/proposta (anos 50), moda/ prótese (anos 60 e 70), moda/fetiche (anos 80), moda/ álibi (anos 90) e moda/instalação (anos 2000). Tais etiquetas marcam tendências preponderantes relativamente a questão em pauta. $\mathrm{O}$ que nos sugere o corpo da moda dos anos 50 aos anos 2000? Metáfora ou metonímia do Brasil?

A preocupação em definir o Brasil como nação e o brasileiro como povo, como bem sublinha Lívia Barbosa, ${ }^{2}$ foi um tema central de nosso pensamento intelectual. Os movimentos de busca de identidade nacional sempre se caracterizaram pelo desejo de unificação, de banimento do outro, seja através de um exotismo paradisíaco, encenado por exemplo no romantismo, seja por um exotismo mestiço que, no limite, perdia a abertura das diferenças para encarnar um mito.

Tradicionalmente, ao se falar de identidade nacional, o que se tinha em mente era uma comunidade imaginada, unificadora do povo a ser administrada por um Estado em busca do progresso. Dentro de uma perspectiva evolucionista Silvio Romero, bem como Euclides da Cunha ou Nina Rodrigues, no século XIX, viram no elemento mestiço uma maneira de considerar a impossibilidade de transplantar integralmente o desenvolvi-

\section{Nízia Vilaça ECA/UFRJ}


mento europeu. Era necessário esperar o processo de branqueamento social.

Definir o nacional foi uma luta ideológica que atravessou diversos momentos históricos, notadamente, os anos 20 com o Movimento Modernista, com a antropofagia e também a década de 30 com a obra representativa de Gilberto Freyre que inverte o sentido de mestiçagem atribuindo-lhe positividade. Mantém, entretanto, o modelo que encobre conflitos raciais, trocando raça por cultura. Para seguir o trajeto aludido no título "Brasil: da identidade à marca", faremos breve retrospecto da expansão do mercado da moda nas décadas aludidas, da importância crescente do mundo "fashion" em tempos globais, assinalando as transformações das relações nos e dos espaços, geográficos e simbólicos, por meio da comunicação mediada pela moda e suas estratégias de subjetivação cuja tônica apela para o corpo.

O cenário sócio-histórico sempre articulou comportamentos em que a estética corporal era recriada e transformada no jogo social e algumas vezes no jugo social. A primeira de nossas categorias, a moda proposta, refere-se aos anos 50, momento em que a sociedade de consumo começa entre nós a delinear seu perfil e em que o corpo brasileiro está atrelado a todo um imaginário fashion que era importado.

O cinema e a televisão disseminavam as imagens do American Way of Life. A produção era massiva e o consumo também. O período Kubitscheck se caracteriza pela internacionalização da economia brasileira no momento que, paradoxalmente, procuravase um ideário nacionalista. Desenvolve-se a indústria automobilística e têxtil. Cinqüenta anos em cinco era a meta e a inauguração de Brasília, um marco. A revista "Jóia", junto com a "Manequim" e sua substituta "Desfile", foram pioneiras no sentido de acompanhar o crescimento da indústria nacional e apresentar a moda dentro do estilo fabricado no Brasil baseado em modelos europeus. Pela primeira vez as pessoas comuns podem ter acesso às criações da moda sintonizadas com as tendências do momento. Em 55, as revistas "Elle" e "Vogue", dedicam várias páginas às coleções prêt-à-porter. $\mathrm{O}$ modelo feminino é branco, jovem e esguio. A saia lápis impede os movimentos. Nas fotos, a postura é rígida e freqüentemente, não há relação entre a roupa e o cenário. Nara Leão com seu cabelinho de franja, sua pequena voz, vestido até o joelho, era a grande sensação das camadas média e alta das classes média. Pura Bossa Nova. Havia regras de decoro de acordo com a hora, cuidados com os acessórios para a classe média de um modo geral.

Enquanto isso, sobretudo, na segunda metade da década, em pontos dos Estados Unidos, discutiamse os beatnicks ${ }^{3}$ e o existencialismo (vestuário semelhante ao dos punks ${ }^{4}$ dos anos 70), escutava-se música afro-americana, entregavam-se ao rock and roll, quando o programa não era lançar-se on the road. Jovens rebeldes como Marlon Brando, James Dean ou Bill Haley, não se submetiam a indumentária da época e Elvis Presley dava a nota. Tal clima de alguma forma nos chega através do filme "Sementes de Violência", 1955. Anunciava-se a revolução comportamental dos anos 60.

Já nos anos 60 e 70, que vamos denominar de moda prótese, a moda constitui-se como uma extensão do corpo para expressar linhas de liberdade, contestação e novos imaginários como o espacial, revelando crescente integração com o mundo devido ao desenvolvimento da comunicação em geral. $\mathrm{O}$ início da década é marcado pela arte revolucionária do CPC que leva aos extremos o pensamento sobre conscientização política, iniciado pelo ISEB. ${ }^{5}$ A discussão sobre o que seja o povo brasileiro toma conta do Movimento Teatral, Movimentos Estudantis e Políticos.

Em 64, o Golpe e a Ditadura. É como se houvesse dois países: o Pop e o da Contracultura. ${ }^{6} \mathrm{O}$ novo ídolo da classe média das sociedades de massas é Roberto Carlos. O programa Jovem Guarda é acompanhado de poderoso marketing. A marca Calhambeque dissemina-se em toda uma gama de produtos. O disco é vendido no exterior e, na América Latina, conseguia tanta fama quanto o "Tico-Tico no Fubá" ou "Aquarela do Brasil". É a época dos tubinhos que substituem as saias rodadas do new look. Era o duas peças e a calça saint tropez na corrida pela liberdade de movimentos. A indústria nacional desencadeia uma ofensiva das fibras sintéticas: banlon, tergal, nylon, acrílico, rayon e poliester. Em 65, as saias tornam-se mais curtas, os temas gráficos substituem as estampas, os Beatles influenciam a moda jovem. Mary Quant lança a minissaia. Londres é a grande influência. A moda unissex insinuase. A novela Beto Rockfeller revoluciona a área na TV Tupi.

A discussão sobre países desenvolvidos e periféricos desenvolve-se através de ensaios políticos que se sucederão até 68, quando o AI-5 marcará um endurecimento do Regime. Em Paris, o Movimento 68; as manifestações estudantis, no Brasil: desbunde e luta armada. Apesar da ditadura, há um estímulo controlado da cultura e a criação de instituições estatais que a organizam, como por exemplo o Conselho Federal de Cultura, a EMBRATUR ou o Instituto Nacional do Cinema. A década é marcada tanto por um movimento de superfície, quanto por uma real revolução em termos de comportamento. A censura marca a distância entre os dois. A classe média prossegue com a tipologia das boutiques, enquanto muitos são presos e exilados.

A escolha de estilo amplia-se. O corpo através das roupas, se solidariza com os movimentos mundiais, mas lança sua especificidade brasileira como bem demonstra o fenômeno Tropicalismo que lança duas marcas brasileiras que até hoje contam um pouco de nossa história: Caetano Veloso e Gilberto Gil.

Os anos 70 dão continuidade aos anos 60. A revis- 
ta "Nova", lançada em outubro de 1973, pela editora Abril, veio para informar a mulher dos anos 70 que, aos poucos, ia libertando-se do lar e conquistando seu espaço na sociedade. Era indicada às solteiras ou casadas, mas com um perfil profissional e com uma certa liberdade sexual. Figura emblemática desta década foi a mineira Zuzu Angel com loja em Ipanema, levando a moda brasileira para o então desacreditado mercado americano. Explorou materiais nacionais, valorizou seu nome ao colocar a etiqueta do lado de fora e, em famosa coleção, fez alusões gráficas a morte de seu filho Stuart, morto pelo regime militar em 70. Criava não só para a elite, mas para a mulher comum. Apesar de ainda haver muita cópia, os costureiros brasileiros já davam seus passos em busca de uma moda nacional, mostrando seus trabalhos nas páginas das revistas femininas. Dener foi o primeiro ainda nos anos 50 e sua vida, descrita por Carlos Dória, ${ }^{7}$ nos dá um retrato da dinâmica nacional/estrangeiro entre os anos 50 e 78, quando falece. Qual a fábrica estrangeira que tem etiqueta brasileira? - perguntava o costureiro notando a decadência do setor no Brasil. Queixava-se da moda estrangeira trazida pelos "compristas brasileiros" (eufemismo para muambeiros). O governo passou, depois, a taxar com importação, as compras feitas acima de 200 dólares.

\section{Dando continuidade ao aspecto espetacular já presente nos anos 90, acentua-se a importância de inventar e manter a marca com estratégias que suscitam interatividade.}

Passando pela moda hippie, pelas discotecas (novela "Dancing Days" e seu figurino psicodélico), pelo "No Future" dos punks (Sex Pistols), pelo clímax do jeans, os anos 70 entre nós se fecham com a anistia e a tanga do Gabeira nas Dunas de Ipanema, significando a maior liberação política refletida nos corpos.

No plano mundial temos Tatcher e Bush, e a crescente importância do neoliberalismo. Com a moda/ fetiche ainda mais que o corpo importa a grife. É a época do desenvolvimento das multinacionais, dos shopping centers e a importância das marcas assume o relevo de fetiches que parecem anular o próprio corpo. A construção das marcas e desenvolvimento da comunicação caminham paralelamente e as estratégias para criar e manter a importância da marca não parará mais. É nesta época que cresce o movimento profissional das mulheres cujo poder é regis- trado nos tailleurs com ombreiras. No campo do lazer, elas constróem seus corpos, e as grifes ligadas ao esporte ganham importância. Como outras tendências da época cabe assinalar a explosão das tribos: punks, góticos, skinheads, new wavers, rappers. As grifes japonesas entram em cena com a desestruturação da silhueta, apoiada em pesquisa têxtil. Surgem as top models.

Nos anos 90, a moda que chamamos de moda/álibi, vai utilizar no mercado da moda os recursos provenientes da política multicultural e do politicamente correto. A etiqueta álibi vem aludir ao deslocamento das questões ligadas à ética e à política para o fórum global das passarelas e veículos do mundo fashion. $\mathrm{O}$ Brasil se beneficia desta abertura à diferença. O corpo vestido torna-se outdoor ético, político, tribal. Iniciam-se os megadesfiles, iniciando-se com o Phytoervas Fashion, de Paulo Borges. Surgem desfiles autorais de Fause Haten e Marcelo Sommer. Debate-se a identidade nacional com estilistas, fotógrafos, produtores etc. O Brasil tem sucesso no prêt-àporter de Paris com Ocimar Versolato. O corpo da brasileira é objeto de desejo. O Brasil começa a tornar-se objeto de exportação e, progressivamente, instala-se o ir e vir do nacional e do estrangeiro no campo da moda, por ocasião dos desfiles. Cabe lembrar o surgimento da figura do stylist que, como acentua Erika Palomino, ${ }^{8}$ não é o estilista, mas um super produtor de moda que define o look e faz ponte com todos os envolvidos. Ele deve conhecer história da arte, história da moda, acompanhar o mundo da música e do cinema. Acrescentaria cultura e política. Os anos 90 ampliam definitivamente o horizonte do planeta fashion, generalizando apropriações no espaço e no tempo. A moda discute ciência, estética e ética.

Os anos 2000, no contexto da globalização da sociedade de consumo, cresce a preocupação com a Marca Brasil, explorado como um grande celeiro de criatividade e talentos nos mais diversos campos. Uma tendência predominante, entre as estratégias adotadas, é o recurso ao imaginário da arte na sua versão instalação: moda/instalação. Enfatiza-se a imagem do país no cenário global, oferecendo criatividade e desenvolvimento tecnológico. O empréstimo, tomado ao campo artístico, aponta para o processo de construção da identidade como esforço histórico e não essência ou substância. Na trilha dos tropicalistas, a apropriação e a hibridação dão o tom. Dando continuidade ao aspecto espetacular já presente nos anos 90 , acentua-se a importância de inventar e manter a marca com estratégias que suscitam interatividade, imersão ambiental, intertextualidade e outros recursos constitutivos da produção e percepção contemporâneas no campo das artes. Na São Paulo Fashion Week de 2005, o prédio da Bienal se transforma numa grande instalação em que as 10 mil pessoas, que freqüentam o evento diariamente, entram como participantes. Giselle Nasser, talento da nova geração, garante, por ocasião 
de sua seleção para o SPFW 2004, que não vai perder sua identidade. "Vou ficar mais comercial, não no sentido de estilo, mas no sentido de produção, de viabilizar a roupa", comenta. ${ }^{9}$

A moda, cujas relações com o campo artístico sempre foram presentes, sofistica seus processos de apropriação estética. Os produtores e estilistas preocupam-se com a elaboração de climas que sugerem a complexidade da subjetivação contemporânea e buscam a interação maior com o público. A possibilidade oferecida a todos parece ser a da escolha do diálogo, da interferência, da reorganização ambiental. Daí a variada dispersão da moda pela cidade como um teatro de rua. Além da questão de propiciar uma provocação para a percepção do contemporâneo, a moda, no seu viés instalação, ${ }^{10}$ cria eventos que, por sua espetacularidade, reforçam a marca como mais importante do que qualquer outra característica do produto. A gestão da marca é o grande desafio no capitalismo de imagens que não pára de criar pseudo-sujeitos e pseudo-acontecimentos. A marca fabrica verdadeiros romances e narrativas provenientes de diversos campos.

\section{Segundo Martín-Barbero, é o mercado capitalista que pressiona o sentido da formação de identidades locais.}

No lançamento outono-inverno 2006 no MAM, a palavra clima dominou, apontando o tema "Horticultural" e a necessidade de conexão com o ecossistema. Segundo Eloysa Simão, organizadora do evento, "essa mistura remete à herança carioca onde favela e asfalto se encontram". Segundo a holandesa Li Edelkoort, uma das maiores trendsetters, muita inspiração para o verão 2007, será compilada no tema "Museu de história natural". ${ }^{11} \mathrm{Na}$ mesma viagem climática, Maria Fernanda Lucena espalhou tinta pela passarela para nos passar a percepção de aula de pintura do Parque Lage. É interessante notar que dentro desta proposta da moda como instalação, tanto se criam ambientes, quanto se reestruturam outros com intervenções e propostas fashion, ou seja, trabalhos preparados para ambientes previamente escolhidos.

Na cultura de mercado é a diversidade que cria a unidade. Segundo Martín-Barbero, é o mercado capitalista que pressiona o sentido da formação de identidades locais. "A identidade local é assim levada a se transformar em uma representação da diferença que possa fazê-la comercializável, ou seja, submetida ao turbilhão das colagens e hibridações que impõe o mercado". ${ }^{12}$ Da diferença cultural ao diferencial da marca. Segundo Isleide Arruda Fontenelle, ${ }^{13}$ a importância atribuída à marca provém de um processo de compensação pela implosão constante de todas as formas resultantes de uma cultura descartável. A marca parece com a ilusão da forma que dá ao sujeito o sentido de permanência já que as imagens se deslocam o tempo todo em torno do nome que é fixo.

Na esteira deste sucesso o governo lançou a Marca Brasil para promover os produtos e serviços brasileiros no exterior, um esforço da FIESP, do Ministério do Desenvolvimento e do Turismo, Ministério do Turismo e do presidente da EMBRATUR, após pesquisa feita com empresas e estrangeiros que visitaram o Brasil.

O presidente da FIESP disse que a marca vai agregar valor aos produtos brasileiros. Segundo o ministro do turismo a marca é fundamental porque dá forma, cor e visibilidade a um conjunto de sentimentos que nós sempre tivemos no país. Cabe lembrar a importância que assume o design como bem mostra a criação do prêmio "Brasil Faz Design", com o apoio de várias instituições públicas e empresas particulares. A identidade agora é vendida na diversidade. ${ }^{14}$

Cabe assinalar como reflexão final que a questão das marcas tanto aparece como estratégia do mercado contemporâneo em detrimento do Estado que buscava o bem-estar social, como tem sido usada por grupos de excluídos e periféricos que negociam suas identidades. Um exemplo dessa dinâmica pode ser visto no caso Daspu/Daslu. Segundo Paolo Virno, ${ }^{15}$ em movimentos deste tipo, o povo não é visto como um abstração paralela a idéia de Estado e de democracia representativa, mas como multidão cuja singularidade vai se revelando processualmente. Tal fato não exclui a possibilidade de apropriações provenientes de um Estado que utiliza práticas de workfare, "palavra de ordem para uma mobilização total da população para o trabalho na era financeirizada da produção de imagens e de signos" ${ }^{16}$ - Famecos

NOTAS

1. DOUGLAS, Mary e ISHERWOOD, Baron. O mundo dos bens: para uma antropologia do consumo; tradução Plínio Dentzien. Rio de Janeiro: Ed. UFRJ, 2004.

2. BARBOSA, Lívia. "O Brasil pelo avesso: Carnavais, malandros e heróis e as interpretações da sociedade brasileira". In: GOMES, Laura Graziela; BARBOSA, Lívia e DRUMMOND, José Augusto. (orgs.). In: O Brasil não é pra principiantes: Carnavais, malandros e heróis, 20 anos depois. Rio de Janeiro: FGV, 2000. pp. 43-59.

3. BUENO, André e GÓES, Fred. O que é Geração Beat. Col. Primeiros Passos, n. 130. São Paulo: Brasiliense, 1984. 
4. BIVAR, Antônio. O que é Punk. Col. Primeiros Passos, n. 76. São Paulo: Brasiliense, 1982.

5. Segundo Renato Ortiz, a função dos intelectuais seria diagnosticar os problemas da nação e apresentar um programa a ser desenvolvido. Caberia a burguesia progressista esta tarefa. In: A moderna tradição brasileira. 5 ed. São Paulo: Brasiliense, 1994. pp. 63-65.

6. PEREIRA, Carlos Alberto Messeder. O que é contracultura. Col. Primeiros Passos, n. 100. São Paulo: Brasiliense, 1983.

7. DÓRIA, Carlos. Bordado da fama: uma biografia de Dener. São Paulo: Ed. SENAC São Paulo, 1998.

8. PALOMINO, Erika. A moda, 2 ed. São Paulo: Publifolha, 2003 - (Folha explica).

9. PALOMINO, Erika. "Neon e Giselle Nasser vão bombar". In: Folha de S. Paulo. Caderno Ilustrada, 3 de dezembro de 2004, p. E-6.

10. Ver sobre o assunto: COSTA, Cacilda Teixeira da. Arte no Brasil 1950-2000: movimentos e meios. São Paulo: Alameda, 2004.

11. Ver site: http://www.idaproject.com (Dumas Amenidades, 11 de janeiro de 2006 - especial Fashion Rio).

12. MARTÍN-BARBERO, Jesús. Dos meios às mediações: comunicação, cultura e hegemonia; prefácio Néstor García Canclini; tradução Ronald Polito e Sérgio Alcides. Rio de Janeiro: Ed. UFRJ, 1997. p. 28.

13. FONTENELLE, Isleide Arruda. O nome da marca: McDonald's, fetichismo e cultura descartável. São Paulo: Boitempo Editorial, 2002.

14. PORTES, Ivone. Folha Online. "Governo cria marca para promover produtos e serviços do Brasil no exterior". Ver site: http:// www1.folha.uol.com.br/folha/dinheiro/ ult9lu93571.shtml

15. VIRNO, Paolo. "Política e felicidade". In: Revista Global Brasil, n. 5, maio/junho/julho, 2005. pp. 30-33.

16. HOLMES, Brian. "Os museus na era do workfare generalizado". In: Revista Global Brasil, n. 5, maio/junho/julho, 2005. pp. 38-40.

\section{REFERÊNCIAS}

BIVAR, Antônio. O que é Punk. São Paulo: Brasiliense, 1982. Coleção Primeiros Passos, n. 76.

BUENO, André e GÓES, Fred. O que é Geração Beat. São Paulo: Brasiliense, 1984. Coleção Primeiros Passos, n. 130.

COSTA, Cacilda Teixeira da. Arte no Brasil 19502000: movimentos e meios. São Paulo: Alameda, 2004.

DÓRIA, Carlos. Bordado da fama: uma biografia de Dener. São Paulo: Ed. SENAC São Paulo, 1998.

DOUGLAS, Mary e ISHERWOOD, Baron. O mundo dos bens: para uma antropologia do consumo; tradução Plínio Dentzien. Rio de Janeiro: Ed. UFRJ, 2004.

Folha de S. Paulo. Caderno Ilustrada, 3 de dezembro de 2004.

FONTENELLE, Isleide Arruda. O nome da marca: McDonald's, fetichismo e cultura descartável. São Paulo: Boitempo Editorial, 2002.

GOMES, Laura Graziela; BARBOSA, Lívia e DRUMMOND, José Augusto. (Orgs.). $O$ Brasil não é pra principiantes: Carnavais, malandros e heróis, 20 anos depois. Rio de Janeiro: Editora FGV, 2000.

MARTÍN-BARBERO, Jesús. Dos meios às mediações: comunicação, cultura e hegemonia; prefácio Néstor García Canclini; tradução Ronald Polito e Sérgio Alcides. Rio de Janeiro: Ed. UFRJ, 1997.

ORTIZ, Renato. A moderna tradição brasileira. 5 ed. São Paulo: Brasiliense, 1994.

PALOMINO, Erika. A moda, 2 ed. São Paulo: Publifolha, 2003 - (Folha explica).

PEREIRA, Carlos Alberto Messeder. O que é contracultura. São Paulo: Brasiliense, 1983. Coleção Primeiros Passos, n. 100.

Revista Global Brasil, n. 5, maio/junho/julho, 2005.

Site: http:/ / www.idaproject.com

Site: http:/ / www1.folha.uol.com.br/folha/ dinheiro/ult9lu93571.shtml 